\title{
PENATALAKSANAAN SINDROMA MAYER ROKITANSKY KUSTER HAUSER (SINDROMA MRKH) DENGAN SINDROMA KLIPPEL FEIL
}

\author{
(MANAGEMENT MAYER ROKITANSKY KUSTER HAUSER SYNDROME \\ WITH KLIPPEL FEIL SYNDROME)
}

\author{
Arsana Wiyasa IW, Aisyatul Mukminah \\ Laboratorium / SMF Obstetri dan Ginekologi FK Unibraw
}

\begin{abstract}
It was reported that a 19 year old woman, suffered from Muller duct agenesis. The patient came to RSSA, complained about primary amenorrhea and assimetrical of head position. Tuba, uterus and 2/3 proximal vagina were not formed. Both of ovaries seemed normal. Based on vaginal sondage, the vagina canal is only $1.5 \mathrm{~cm}$. Secondary sexual characteristics developed normally. By skull and cervical $X$ - ray, it was found fusion of vertebrae cervical 3,4 . The vagina and the uterus are not present, but the tuba and the ovarium are normal; this case is known as Mayer Rokitansky Kuster Hauser Syndrome. Moreover, it is accompanied by another congenital defect, i.e. fusion of vertebrae cervical 3 and 4, which is called Klippel Feil Syndrome. In the exploration, it was found that there was a constitution of cromosom 46,XX. It has been done hormonal examination: $F S H, L H$, estrogen, prolactin and was obtained testosteron < $127.8 \mathrm{ng} / \mathrm{dl}$. The patient was grews up as a woman. Her behavior, attitude, emotion and sexual behavior are likely a woman. We plan to perform and suggest her to adopts a child. To treat the Klippel Feil, it is important prevention of the neck trauma and complication of neurology and arthritis.
\end{abstract}

Key word : Mayer Rokitansky Kuster Hauster Syndrome, Klippel Feil Syndrome, vaginoplasty

\section{PENDAHULUAN}

Amenore adalah keadaan tidak datangnya haid untuk sedikitnya 3 bulan berturut-turut $(1,2,3)$. Secara umum dibedakan menjadi 2, yaitu Amenore fisiologis (pra pubertas, hamil, laktasi, pasca menopause) dan Amenore patologis terdiri dari Amenore primer dan Amenore sekunder. Definisi Amenore primer adalah sampai umur 14 tahun belum mengalami menstruasi disertai belum berkembangnya tanda seks sekunder atau sampai umur 16 tahun belum mengalami menstruasi, Namur tanda seks sekunder berkembang normal $(1,2,3,4)$.

Salah satu tanda dari kelainan kongenital yang mengenai genitalia perempuan adalah Amenore primer. Kelainan kongenital yang paling sering dijumpai diantaranya adalah gangguan pembentukan vagina yaitu Sindroma Mayer Rokitansky Kuster Hauser (Sindroma MRKH). MRKH merupakan sindroma tidak terbentuknya vagina, uterus dan saluran telur (tuba) yang berasal dari ductus Muller, genitalia eksterna, ciri kelamin sekunder dan sitogenetik normal wanita $(4,5)$.

Etiologi dari Sindroma MRKH belum jelas. Secara embriologi diketahui, bahwa terjadinya gangguan perkembangan fusi ductus Muller pada kehamilan minggu ke sembilan $(5,6,7)$. Sindroma MRKH merupakan bagian dari kelainan agenesis vagina atau ductus Muller, yang dapat disertai kelainan organ tubuh lain seperti, tulang belakang, ekstremitas dan tractus urinarius $(7,8)$. Sindroma Klippel Feil adalah terjadinya kegagalan segmentasi dari mesodermal somite pada kehamilan minggu ke delapan atau lebih. Sindrom ini sering terjadi pada wanita dari pada pria. Biasanya disertai juga kelainan organ tubuh lain

Jurnal Kedokteran Brawijaya, Vol. XX, No.2, Agustus 2004.

Korespondensi: Soewarto S; Sub Bagian Fetomaternal SMF Obstetri dan Ginekologi FK Unibraw; JI. Veteran Malang-65145; telp (0341) 580993, 567192 fax (0341)564755. seperti, sprengel deformity, renal agenesis, deafness dan arthritis $(9,10)$.

Angka kejadian Sindroma MRKH dan Sindroma Klippel Feil sangat jarang, apalagi jika terjadi bersamaan. Pada sindroma MRKH penderita biasanya mengeluh tidak menstruasi (amenore primer), gangguan hubungan seksual dan infertilitas. Untuk menegakkan diagnosa Sindroma MRKH tidak sulit, namun memerlukan biaya mahal karena memerlukan pemeriksaan kromosom, endokrinologi, radiologi. Hal ini merupakan kendala bagi penderita yang tidak mampu. Penegakan diagnosa pada masa bayi atau anak sangat sulit. Sedangkan fusi vertebra cervical dari pemeriksaan radiologi $(11,12,13)$.

Penanganan penderita dengan MRKH dapat dilakukan dengan cara memperbaiki fungsi seksualnya dengan cara melakukan rekontruksi vagina (vaginoplasti). Perbaikan ini perlu dilakukan bila penderita secara fisiologis menerima keadaannya. Vaginoplasti dikerjakan bila penderita sudah matang kejiwaannya dan ciri kelamin sekunder sudah nampak.

Pada tulisan ini akan dilaporkan sebuah kasus yang jarang terjadi, yaitu seorang penderita dengan sindroma MRKH.

Pada penderita ini disertai dengan kelainan kongenital yaitu fusi vertebra cervical 3 dan 4, atau Sindroma Klippel Fiel $(6,7,14)$.

\section{LAPORAN KASUS}

Seorang perempuan, umur 19 tahun, suku Jawa Indonesia, pendidikan setingkat SMU, datang ke poli Fertilitas Endokrinologi Reproduksi (FER) RSUD dr Saiful Anwar Malang. Penderita datang dengan keluhan belum pernah menstruasi. Pada anamnesa keluarga saudara kandungnya tidak ada mengalami sakit seperti penderita.

Pada pemeriksaan fisik didapatkan postur normal Tinggi Badan (TB): $148 \mathrm{~cm}$, leher asimetris / bentuk leher yang tidak 
simetris, extensi normal, flexi menurun. Payudara normal (Tanner 3/3), rambut axilla minimal.

\section{Status ginekologis.}

Labia mayora dalam batas normal, labia minora dalam batas normal, hymen intak, clitoris dalam batas normal, sondage vagina $6 \mathrm{~cm}$, colok dubur tonus sphingter ani normal, mukosa ani licin, corpus uteri kesan hipoplasia, parametrium kanan dan kiri massa tidak ada, nyeri tidak ada.

Hasil pemeriksaan laboratorium kadar hormon estrogen, FSH, LH, testosteron dan prolactin dalam batas normal.

\section{Pemeriksaan penunjang lain :}

Pemeriksaan karyotiping $46 \mathrm{XX}$, pemeriksaan USG uterus tidak tampak (agenesis uteri). Hasil pemeriksaan suhu basal biphasik.

\section{Foto polos kepala :}

Canalis acuticus dextra dan sinistra normal, tulang-tulang wajah normal, tampak fusi corpus vertebra cervical 3-4. Sella tursica : procesus clinoideus anterior dan posterior baik. Clivus intak,tidak didapatkan tanda-tanda Space Occupiying Proces (SOP). Kesimpulan: fusi vertebra cervical 3-4.

\section{DISKUSI}

\section{Diagnosa Sindroma Mayer Rokitansky Kuster Hauser:}

Sindroma Mayer Rokitansky Kuster Hauser merupakan keadaan tidak terbentuknya vagina dan uterus yang berasal dari ductus Muller. Pada kasus ini penderita datang dengan keluhan utama amenorea primer dengan hasil pemeriksaan tidak ada uterus dan liang vagina $1,5 \mathrm{~cm}$.

Pada pemeriksaan karyotiping dapat diketahui bahwa konstitusi penderita ini adalah 46,XX. Dengan demikian dapat disimpulkan bahwa secara genetik penderita adalah wanita $(15,16)$. Tidak ada kelainan autosom maupun kromosom pada penderita ini.

Pada kasus ini diferensiasi gonad dapat ditentukan dengan pembuktian secara tidak langsung dengan USG dan MRI ternyata tidak ditemukan uterus dan tuba. Sedangkan fungsi ovarium bisa diketahui dari status hormonal yang normal yaitu FSH: 2,79 mlU/ml, LH: $5,99 \mathrm{mlU} / \mathrm{ml}$, estradiol: $68 \mathrm{pg} / \mathrm{ml}$. Secara klinis didapat suhu basal badan biphasik Namun demikian untuk mengetahui fungsi dari testis dapat dilakukan pembuktian secara tidak langsung dengan pemeriksaan kadar testosterone yang mencapai < 128,7 ng/dl. Hal ini menunjukkan tidak adanya aktifitas sel-sel Leydig pada testis.

Hasil ini lebih rendah dari gambaran hormonal pria dewasa normal. Seperti kita ketahui bahwa testosterone dihasilkan oleh sel-sel Leydig testis $(17,18,19)$. Sampai saat ini tidak ada jaringan/organ lain atau mekanisme lain yang dilaporkan dapat menghasilkan testosterone dalam jumlah besar selain sel-sel leydig testis, kelenjar adrenal dan ovarium juga dapat menghasilkan testosterone namun dalam jumlah sedikit. (18). Hal ini memperkuat bukti bahwa tidak terjadi perkembangan jaringan testis dalam kasus ini.

Pada pemeriksaan fisik didapatkan bahwa vagina yang terbentuk adalah hanya sepertiga distal dengan vaginal pouch yang pendek sekitar $1,5 \mathrm{~cm}$, sedangkan $2 / 3$ bagian proksimal vagina dan uterus kesan tidak terbentuk. Hal ini membuktikan bahwa terjadi regresi ductus Muller secara lengkap.
Pada kasus ini perkembangan genitalia eksterna memperlihatkan genitalia kearah wanita. Sinus urogenitalis tidak menutup, tetapi tetap terbuka membentuk vagina pouch.

Perkembangan ciri-ciri seks sekunder pada penderita yang berumur 19 tahun ini adalah: payudara berkembang (tanner 3), otot rangka berkembang sesuai wanita normal, rambut pubis berkembang (tanner 3), rambut ketiak/tubuh berkembang. Perkembangan ciri-ciri seks sekunder pada wanita dipengaruhi oleh adanya hormon estrogen $(17,18,19)$. Pada kasus ini perkembangan tanda seks sekunder baik, dan hasil pemeriksaan estrogen didapatkan normal, hal ini disebabkan oleh cukupnya reseptor estrogen yang menangkap hormon estrogen tersebut.

\section{Diagnosa Sindroma Klippel Feil :}

Sindroma Klippel Feil adalah kelainan kongenital berapa fusi vertebra cervical, yang mengakibatkan terjadinya fusi dua atau lebih vertebra cervical $(13,20,21,22)$.

Pada penderita ini didapatkan fusi vertebra cervical 3-4. Fusi vertebra cervical menurut Feil termasuk tipe II, oleh karena fusi antara vertebra cervical terbatas pada interspace cervical $(23,24,25)$. Ditemukan pada saat pemeriksaan klinis adanya asimetris wajah, tanpa torticollis.

Pada kasus ini tidak disertai malformasi organ multipel, seperti agenesis ginjal, kelainan spinal atau deformitas Sprengel. Didapatkan keterbatasan gerak leher, terdapat flexi kepala minimal, extensi kepala normal, tidak didapatkan komplikasi defisit neurologis atau arthritis.

Secara embriologi terjadi kegagalan segmentasi dari mesodermal somite, dimana pembentukan columna vertebralis dimulai dengan migrasi, segmentasi dan diferensiasi dari mesodermal somite pada minggu III-VIII kehamilan $(26,27,28)$. Banyak terjadi pada wanita, walaupun secara genetik belum diketahui pasti, tidak didapatkan kelainan tersebut pada keluarga $(24,25,29)$.

\section{Penatalaksanaan}

Bila diagnosa sudah ditegakkan, maka yang terpenting selanjutnya adalah memberikan informasi dan menuntun penderita untuk memahami penyakit yang diderita serta memahami sikap yang akan diambil. Beberapa hal yang perlu disampaikan antara lain: pertumbuhan yang abnormal dari genitalia interna, akibat kelainan tersebut pada penderita, kemungkinan bisa menikah, kemungkinan bisa melakukan hubungan kelamin, tetapi tidak menstruasi setelah operasi, dan juga tidak bisa hamil. Hal yang mesti menjadi pertimbangan untuk melakukan tindakan rekonstruksi operatif pada vagina yaitu kedalaman kurang dari $4 \mathrm{~cm}(30,31,32)$.

Sebelum dilakukan tindakan perlu dilakukan konsultasi dengan bagian psikiatri untuk kesiapan penderita menerima penyakitnya dan keyakinan tentang keuntungan operasi. Juga sebaiknya dianjurkan untuk adopsi anak. Pasien dengan agenesis vagina kongenital tidak dapat dibentuk menjadi individu secara utuh dengan mudah dengan cara membuat kantong vagina untuk koitus. Peningkatan fungsi seksual hanya salah satu perhatian dan mungkin yang termudah untuk diperbaiki $(33,34,35)$. Revans melaporkan $15 \%$ dari pasiennya memiliki masalah psikiatri yang serius, dia menyarankan bahwa pemeriksaan psikiatri seharusnya dilakukan sebelum tindakan operasi $(35,36,37)$. Dianjurkan melakukan operasi pada usia 
diatas 17 tahun atau 4 - 6 bulan sebelumnya pada penderita yang akan menikah $(18,30,31)$

Pada kasus penderita ini usia 19 tahun, belum menikah, dengan kedalaman vagina $1,5 \mathrm{~cm}$. Hasil konsultasi dengan bagian psikiatri didapatkan penderita dengan masked depressi dan telah dilakukan psikoterapi. Disini jelas diperlukan tindakan operasi rekonstruksi vagina (vaginoplasti). Operasi dapat dilakukan 4-6 bulan sebelum penderita merencanakan pernikahannya $(18,24,30,31)$.

Sedangkan fusi vertebra cervical 3-4 tidak memerlukan suatu tindakan khusus, karena tidak ada kelainan yang menyertai. Yang penting mengurangi kemungkinaan terjadinya komplikasi. Dengan mencegah trauma pada posisi pronasi (tengkurap) dan menghindari olah raga kontak. Terjadinya arthritis dini perlu diwaspadai bila terjadi hipermobilitas tanpa instabilitas pada segmen yang tidak berfusi. Juga diwaspadai tanda-tanda defisit neurologis pada late cervical instability, dan kompresi nerve root.

\section{KESIMPULAN}

Telah dibicarakan suatu kasus, penderita umur 19 tahun dengan amenorea primer. Penderita datang pertama kali dengan keluhan belum pernah menstruasi. Pada pemeriksaan ditemukan:

Konstitusi kromosom 46,XX (kromosom perempuan normal), hasil pemeriksaan hormonal (FSH, LH, estrogen, prolaktin dalam batas normal, testosterone $<127.8 \mathrm{ng} / \mathrm{dl}$ ), Tuba, uterus dan $2 / 3$ proksimal vagina tidak dibentuk, ovarium kesan normal, Genitalia eksterna terbentuk normal dengan liang vagina $1,5 \mathrm{~cm}$, Tanda seks sekunder berkembang normal, Terdapat fusi vertebra cervical 3-4, Sex of rearing: penderita diasuh dan dibesarkan sebagai wanita, Gender role : sikap, perilaku, emosi dan orientasi seksual sesuai wanita.

Gambaran yang diperlihatkan penderita sesuai dengan Sindroma Mayer Rokitansky Kuster Hauser dengan Sindroma Klippel Feil. Penderita memerlukan tindakan rekonstruksi vagina (vaginoplasti) beberapa bulan menjelang pernikahan, telah dilakukan psikoterapi, dianjurkan untuk adopsi anak dikemudian hari. Untuk Sindroma Klippel Feil dilakukan pencegahan terhadap trauma leher dan komplikasi neurologis dan arthritis.

\section{DAFTAR KEPUSTAKAAN}

1. 1. Scherzer WJ, McClamrock, Amenorrrhea. In: Berek JS, Adashi EY, Hillard PA. eds. Novak's gynecology. $12^{\text {nd }}$ ed. Baltimore: Williams \& Willkins; 1996; 809-832.

2. Speroft L, Glasse RH, Kase NG. Amenorrhea in Clinical Gynecologic Endocrinology And Fertility. $5^{\text {th }}$ ed. Baltimore: Williams \& Willkins; 1994; 401-456.

3. Simanjutak P. Gangguan Haid Dan Siklusnya. Dalam: Wiknjosastro H, Saifudin AB, Rahimhadi T, eds IImu Kandungan .ed1. Jakarta: Yayasan Bina Pustaka Sarwono Prawiroharjo; 1994; 152-178.

4. Baziad A, Surjana EJ. Pemeriksaan Dan Penanganan Amenore. Dalam: Baziad A, Jacoeb TZ, Surjana EJ. Eds Endokrinologi ginecologi. Edisi 1. Jakarta: Kelompok Studi Endokrinologi Reproduksi Indonesia; 1993; 35-60.

5. Kletzky OA. Amenorea Dan Perdarahan Rahim Abnormal (terjemahan Nugroho E). Dalam: Hacker NF, Moore JG. Esensial obstetri dan ginecologi. edisi ke 2. Jakarta: Penerbit Hipócrates; 1995; 567-580.

6. Daniel R, Mishell JR, Paul F. eds. Management Of Common Problem In Obstetric Gynecology. $3^{\text {th }}$ eds. Boston: Blackwell Scientific Publication; 1994; 581-588.

7. James E, Griffin MD, Jean P. eds Disorder of Sexual Diffferentiation. In:.Cambell Urology $5^{\text {th }}$ ed Philadelphia: WB Saunders Company; 1986; 1509-1532.

8. Jewelewicz R, Jaffe SB. Amenorrhea. file://A:/MDConsult-Journals9files/1.htm .

9. Fisher K, Esham RH, lan T. Associated With Typical Mayer Rokitansky Kuster Hauser Syndrome. http://www.medscape.com/SMASMJ/2000/v93.n02/smi.9302.22 fish/smi.9302.22 fish -01.html

10. Carter SM. Typical Mayer Rokitansky Kuster Hauser Syndrome. Medicine Journal 2001; 21-29.

11. Hensle TW, Chang DT. Reconstructive Urology Surgical Craft: Laparascopic Live Donor Nephrectomy. Vaginal recontruction. file://A:/MDConsult-Journals4files/1.htm .

12. Nelson S. Mayer Rokitansky Kuster Hauser (Congenital Total Or Partial Absence Of Uterus And Vagina). http://www.nelsonginecologia.med.brl

13. Fujimoto VY, Miller JH, Klein NA. eds. Congenital Cervical Atresia: Report Of Seven Cases And Review Of The Literature. file://A/MDConsult-Journals6file/1.htm.

14. Buku Pedoman diagnosis dan terapi. Surabaya: UPF IImu Kebidanan dan Kandungan FK UNAIR/ RSUD Dr Sutomo. 1994; 95-102.

15. Van Lingen BL, Reindollar RH, Davis AJ. eds. Further Evidence That The Wt1 Genedoes Nota Role In The Development Of The Derivates Of The Mullerian Duct. file://A:/MDConsult-Journals5files/1.htm

16. Edmonds DK. Congenital Malformations Of The Genital Tract. file://A:/MDConsult-Journals3files/1.htm

17. Carter SM. Mayer Rokitansky Syndrome. http://www.emedicine.com/ped/topic1381.htm

18. Speroft L, Glasse RH, Kase NG. Normal And Abnormal Sexual Development In Clinical Gynecologic Endocrinology And Fertility. $5^{\text {th }}$ ed. Baltimore: Williams \& Willkins; 1994; 321-360.

19. Anderson JR, Genadry R. Anatomi and Embryology. In Berek JS, Adhashi EY, Hillard PA. eds. Novaak`s gynecology.12 nd ed. Baltimore: Williams \& Willkins; 1996; 71-122. 
20. Wiknjosastro H. Embriologi Sistem Alat-Alat Urogenital. Dalam: Wiknjosastro H, Saifudin AB, Rachimhadi T. Eds Ilmu Kandungan. edisi 2. Jakarta: Yayasan Bina Pustaka Sarwono Prawiroharjo; 1997; 27-41.

21. Hensinger RN. Congenital Anomalies Of The Cervical Spine. Clin. Orthop; 1992; 264: 16-38.

22. Klippel Feilsyndrom.file://A:IOrthoseek\%20\%200rthopedic\%20Topics\%20\%20Klippel-Feil\%20Syndrome.htm

23. Kahn CE. Klippel Feil syndrome.file://A:Klippel- Feil\%20syndrome.htm

24. Hall JE, Simmon ED, Dhannylchulk K. Instability of The Cervical Spine And Neurological Involvement In Klippel Feil syndrome.file://A:Instability of the cervical spine and neurological involvement $\mathrm{htm}$.

25. Hiperextension injury. file://A:IWheeless'Textbook of Orthopedics.htm.

26. Sadler TW. Sistem Urogenital. Dalam: Sadler TW. Ed.Embryology Kedokteran Langman, Edisi ke 7. Jakarta: Penerbit Buku Kedokteran EGC; 1996; 272-310.

27. Gant Cunningham FG. Sexual Differentiation. In: Gant NF, Cunningham FG, eds Basic Gynecology and obstetrics. 1st ed. Dallas: Prentic-Hall International INC; 1994; 155-162.

28. Frederick WG, Jean, Dwilson. Embryology of The Genitaltractin Cambell' Surology $4^{\text {th }}$ ed. NewYork: Springer Verlag; 1994; 14961505.

29. Gotim RW, Kappy MS, Slover RH. Endocrine Disorder, In: Hay WW, Groothuis JR, Hayward AR. eds. Current pediatric diagnosis \& treatment.13 th ed. Colorado: Appleton \& Lange; 1997; 818-855.

30. Rock AJ. Surgery for Anomalies Of Mullerian Ducts. In: Rock AJ, Thomson JD. Te Linde's operative gynecology. $8^{\text {th }}$ ed.Philadhelpia: Lipincott raven pubhlisers; 1997; 687-730.

31. Rock AJ. Congenital Outflow Tract Obstruction. In: Adashi EY, Rock AJ, Rosenwaks Z. Reproductive endocrynoloigy, surgery, and technology, Philadhelpia: Lippincott raven pubhlisers; 1995; 1446-1473.

32. Cuningham FG, Gant N, Leveno KJ. eds. The Morphological And Functional Development Of The Fetus in William Obstetrics 21 st NewYork: Mc Graw-Hill Companies; 2001; 165-202.

33. Richard J, Worley MD, Johan H, Duenhoulter. Diferensaiasi Seks Abnormal Dan Amenorea Primer. Endokrinologi dasar dan klinik. Edisi ke 4. Jakarta: Penerbit Buku Kedokteraan EGC; 1987; 613-650.

34. Worley RJ. Diferensiasi Seks Abnormal Dan Amenorea Primer. (terjemahan: Sanusi CJ) Dalam: Duenhoulter JN, ed.Ginekologi greenhill.Edisi ke 10 Jakarta: Penerbit Buku Kedokteraan EGC; 1987; 153-183.

35. Conten FA, Grumbach MM. Abnormalities of Sexual Determination \& Diffrentiation. In: Tanagho EA, Mc Aninch JW.Smith's General Urology. International ed .New York: Lange medical books / Mc Graw-Hill; 1992; 698-736.

36. Joseph DB. Embryology The Urogenital System \& Congenital Anomalies Of The Female Genital Tract. In Current obstetrics \& gynecology diagnosis\& treatment $8^{\text {th }}$ ed.Coonecticut: Apleton lange; 1994; 61-92.

37. Mastroianni L, Coutifarris C. Reproductive Physiology. In: Rosenfield A, Fathalla MF. The FIGO manual of human reproduction. New Jersey: The Parthemon Publising Group; 1990; $23-29$.

38. Seibel, M.M., Amenorrhea. In Friedman, E.A., Borten, M., Chapin, D.S., Gynecolocical Decition Making. $2^{\text {th }}$ ed. BC Decker, Philadelphia.1988: 56-57. 

Wiyasa, dkk., Penatalaksanaan Sindroma Mayer Rokitansky ....... 95 